\title{
Abthïzungen.
}

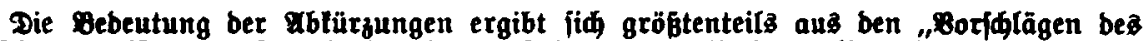

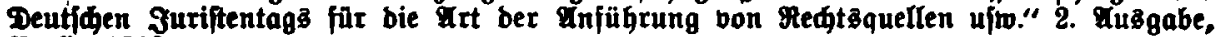
Perlin 1910.

\section{Sonftige Sathizgungen:}

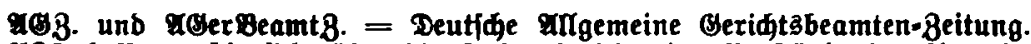

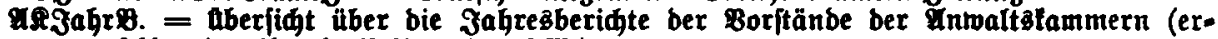
inien jetweils als Beilage ber 328.$)$.

GQB. = Entwaltalammervoritanb.

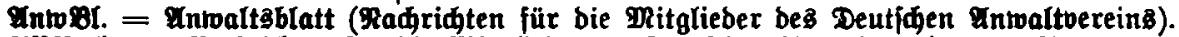

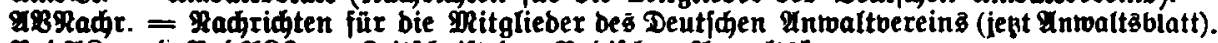

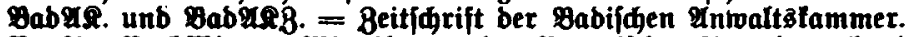

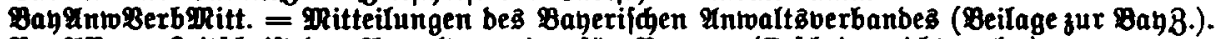

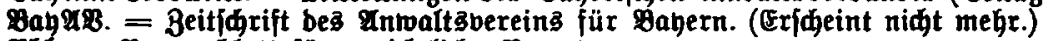

\$bl. = Pureaublatt für geridttide Peamte.

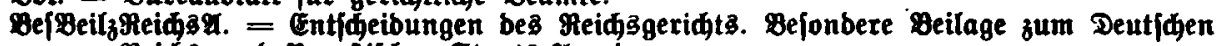

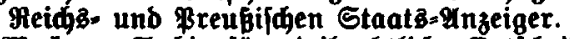

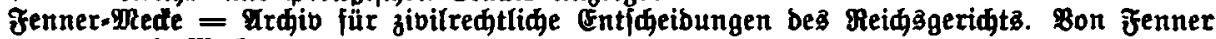
unb IRede.

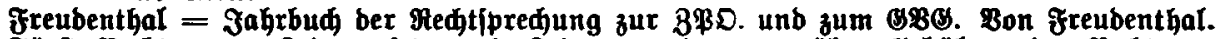

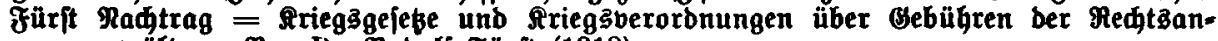
wälte... Bon Dr. ghubolf Fürit (1918).

Jonas = Das beutine Beridtstojtengejes mit Exläuterungen bon Martin \$onas, Berlin 1923.

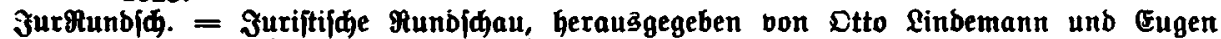
Friebrids (exfter Эahrgang: 1925).

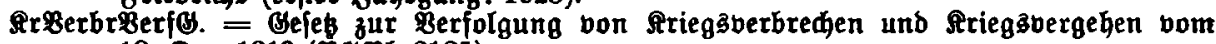

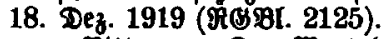

Mittmann = Mittmann, Der $\$$

Sdreibit. = Yür bie Sđ̆reibitube. Beitidrift für ben Bureaubeamtenftanb.

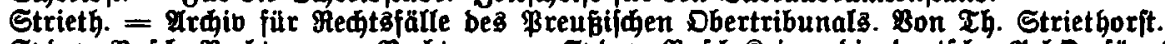

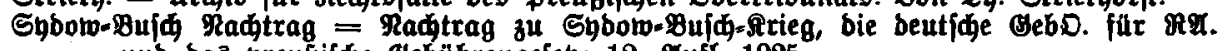

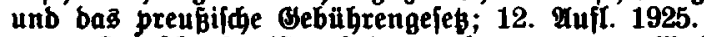

Ballmann = Deutjhe Juriften-Beitung, berauşg. von \$allmann. (Erjןeint nidgt mehr.)

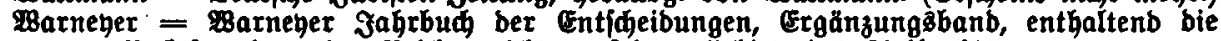

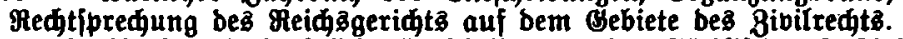

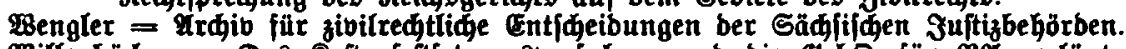

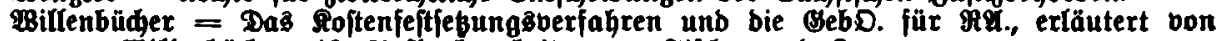

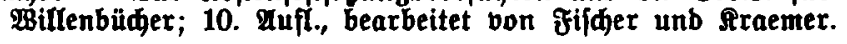

Die befannten Đanbbüđer, Lehrbüder unb Rommentare linb lebiglid nad ben

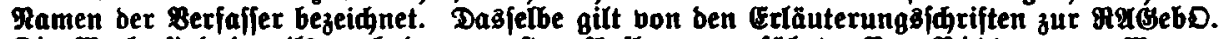

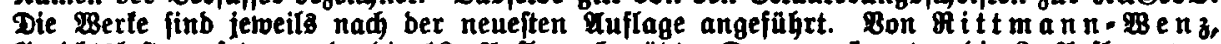

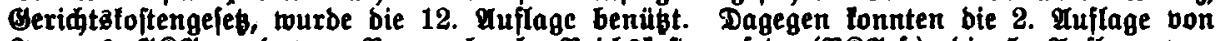

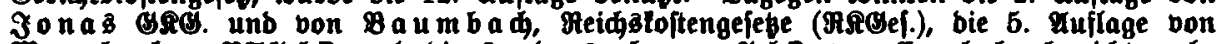

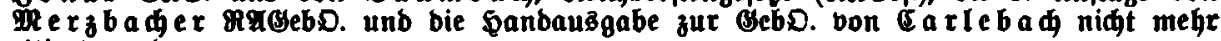
zitiert twerben.

un einzelnen Stellen befinben fid bejonbere Siteraturberzeidniffe, bie zum Berftänbnifje ber Bitate mit zu berüdfidtigen find.

Die Bablen bei Beitínriften (3. \$. 13) bezeidgnen bie giffer be Banbez; wo bie

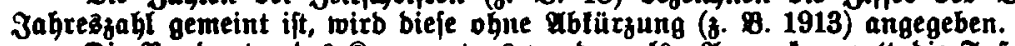
bezeidnet. 